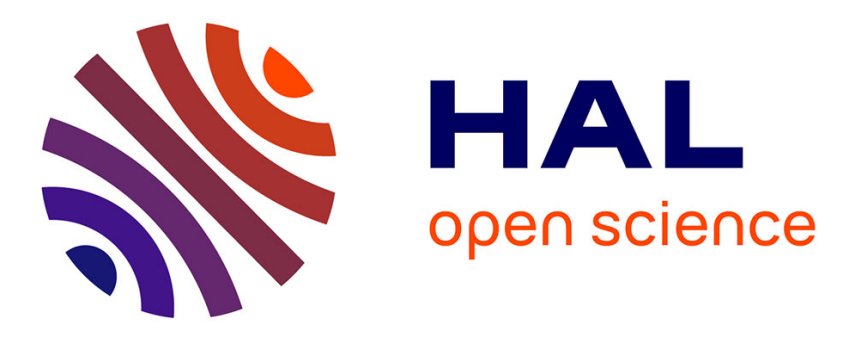

\title{
Triterpene glycosides from the aerial parts of Gouania longipetala
}

Diane Patricia Apie Gossan, Abdulmagid Alabdul Magid, Philomène Akoua

Yao-Kouassi, Antoine Ahibo Coffy, Jérôme Josse, Sophie C. Gangloff, Hamid Morjani, Laurence Voutquenne-Nazabadioko

\section{To cite this version:}

Diane Patricia Apie Gossan, Abdulmagid Alabdul Magid, Philomène Akoua Yao-Kouassi, Antoine Ahibo Coffy, Jérôme Josse, et al.. Triterpene glycosides from the aerial parts of Gouania longipetala. Phytochemistry, 2017, 134, pp.71 - 77. 10.1016/j.phytochem.2016.11.004 . hal-01834083

\section{HAL Id: hal-01834083 https://hal.univ-reims.fr/hal-01834083}

Submitted on 5 Nov 2021

HAL is a multi-disciplinary open access archive for the deposit and dissemination of scientific research documents, whether they are published or not. The documents may come from teaching and research institutions in France or abroad, or from public or private research centers.
L'archive ouverte pluridisciplinaire HAL, est destinée au dépôt et à la diffusion de documents scientifiques de niveau recherche, publiés ou non, émanant des établissements d'enseignement et de recherche français ou étrangers, des laboratoires publics ou privés. 


\title{
Triterpene glycosides from the aerial parts of Gouania longipetala
}

Diane Patricia Apie Gossan ${ }^{\mathrm{a}, \mathrm{b}}$, Abdulmagid Alabdul Magid ${ }^{*}, \mathrm{a}$, Philomène Akoua Yao-Kouassi ${ }^{\mathrm{b}}$, Antoine Ahibo Coffy ${ }^{\mathrm{b}}$, Jérome Josse $^{\mathrm{c}}$, Sophie C. Gangloff ${ }^{\mathrm{c}}$, Hamid Morjani ${ }^{\mathrm{d}}$, Laurence Voutquenne-Nazabadioko ${ }^{\mathrm{a}}$

${ }^{a}$ ICMR-UMR CNRS 7312, Groupe Isolement et Structure, Campus Sciences, Bât. 18, BP 1039, 51687 Reims, France

${ }^{\mathrm{b}}$ Laboratoire de Chimie Organique et de Substances Naturelles, 22 BP 582 Abidjan 22, Université Félix-Houphouët Boigny d'Abidjan-Cocody, Ivory Coast

${ }^{c}$ EA 4691 «Biomatériaux et inflammation en site osseux», Laboratoire de microbiologie, UFR de pharmacie, 1, rue du MaréchalJuin, 51096 Reims, France

d MEDyC UMR CNRS 7369, URCA, Faculté de Pharmacie, SFR CAP Santé, 1, rue du Maréchal-Juin, 51096 Reims, France

* Corresponding author Tel.: +33326918208; E-mail: abdulmagid.alabdulmagid@ univ-reims.fr (Dr. Abdulmagid Alabdul Magid)

\begin{abstract}
Six previously undescribed triterpenoid saponins, gouaniaside I-VI, were isolated from the aerial parts of Gouania longipetala Hemsl. (Rhamnaceae), in addition to four known triterpenes. The structure elucidation of these compounds was based on analyses of spectroscopic data including 1D- and 2D-NMR and HR-ESI-MS techniques. The inhibitory activity of isolated compounds against promyelocytic leukemia HL60 and human erythromyeloblastoid leukemia K562 cell lines was evaluated and jujuboside I exhibited moderate cytotoxicity, with $\mathrm{IC}_{50}$ values of 13.5 and $21.0 \mu \mathrm{M}$, respectively. Among the isolated triterpenes, alphitolic acid exhibited moderate antibacterial activity against Staphylococcus aureus, Enterococcus faecalis and Escherichia coli (MICs 32,64 and $128 \mu \mathrm{g} / \mathrm{mL}$, respectively).
\end{abstract}

Keywords: Gouania longipetala; Rhamnaceae; triterpenoids; antibacterial activity; cytotoxic activity.

\section{Introduction}

Gouania longipetala Hemsl. (Rhamnaceae) is a scandent shrub mainly present in closed-forests and jungle regrowths (Buerki et al., 2011, Burkill et al., 1985). In traditional medicine, decoction or maceration of $G$. longipetala stem bark in local alcoholic drink is used to treat gastro-intestinal problems and gynecological complaints related to gestation and post-delivery hemorrhages (Ezeja et al., 2014). The stem bark extract has been shown to possess antibacterial, anti-inflammatory and antioxidant activities (Ekuadzi et al., 2012, Ezeja et al., 2014). We previously reported the isolation and structural elucidation of two new acylated flavonol glycosides and seven known flavonoids from the methanol extract of $G$. longipetala (Gossan et al., 2015). We continued our investigation of the constituents of the aerial parts of this plant, and isolated six previously undescribed triterpenoid saponins (1-6), together with four known compounds (7-10) from the $\mathrm{MeOH}$ and EtOAc extracts. Compounds 1-10 were evaluated for their inhibitory activity against promyelocytic leukemia HL60 and human erythromyeloblastoid leukemia K562 cells, as well as their antibacterial activity against Staphylococcus aureus, Enterococcus faecalis and Escherichia coli.

\section{Results and discussion}

The ethyl acetate and methanol extracts of the aerial parts of Gouania longipetala Hemsl. (Rhamnaceae) were fractionated and purified separately by combination of chromatographic methods to obtain seven triterpenoid glycosides (1-7) from the methanol extract and three triterpenes (8-10) from the ethyl acetate extract (Figure 1).
The known compounds were elucidated as jujuboside I (7) (Wu et al., 2013), terminolic acid (8) (Jossang et al., 1996), alphitolic acid (9) (Kuang et al., 1989, Suksamaran et al, 2006) and gouanic acid B (10) (Giacomelli et al., 2007) (Figure 1). Their structural assignments were made by HRESI-MS, 1D-, and 2D-NMR analysis. Their spectroscopic data were in perfect agreement with those reported in the literature. In order to determine the sugar composition in these compounds, acid hydrolysis of a part of the saponin mixture generated four sugar units in the aqueous layer, identified after purification and measurement of their optical rotation as D-glucose, D-galactose, L-arabinose and Lrhamnose.

Gouaniaside I (1) was obtained as a white amorphous powder. The positive HR-ESI-MS showed a molecular ion peak at $m / z 789.4409[\mathrm{M}+\mathrm{Na}]^{+}$(calcd for $\mathrm{C}_{41} \mathrm{H}_{66} \mathrm{O}_{13} \mathrm{Na}$, 789.4401), corresponding to the molecular formula $\mathrm{C}_{41} \mathrm{H}_{66} \mathrm{O}_{13}$. The ${ }^{1} \mathrm{H} \mathrm{NMR}$ spectrum of the aglycone part displayed signals of a dammarane triterpenoid characterized by seven tertiary methyl groups at $\delta_{\mathrm{H}} 0.87$, $0.89,1.04,1.15,1.16,1.71$, and 1.74 , three oxygenated methines at $\delta_{\mathrm{H}} 3.13(\mathrm{dd}, J=12.1,4.8 \mathrm{~Hz}, \mathrm{H}-3), 3.68(\mathrm{dd}, J=$ 12.7,3.4 Hz, H-7), 4.70 (ddd, $J=11.2,8.6,1.5 \mathrm{~Hz}, \mathrm{H}-23$ ), an oxygenated methylene at $\delta_{\mathrm{H}} 4.02$ and 4.06 (each d, $J=7.0$ $\left.\mathrm{Hz}, \mathrm{H}_{2}-18\right)$, and a vinyl proton at $\delta_{\mathrm{H}} 5.18(\mathrm{dt}, J=8.6,1.5 \mathrm{~Hz}$, $\mathrm{H}-24)$. Its ${ }^{13} \mathrm{C}$ NMR spectrum exhibited 30 signals including seven methyl groups $\left[\delta_{\mathrm{C}} 13.4(\mathrm{C}-30), 16.5(\mathrm{C}-19), 16.8(\mathrm{C}-\right.$ 29), 18.4 (C-27), 25.8 (C-26), 28.5 (C-28), and 29.7 (C-21)], three oxymethine carbons $\left[\delta_{\mathrm{C}} 69.6,76.0\right.$ and 90.1], an oxymethylene carbon $\left[\delta_{\mathrm{C}} 66.9\right]$, two olefinic carbons $\left[\delta_{\mathrm{C}}\right.$ $126.3(\mathrm{C}-24)$, and $136.8(\mathrm{C}-25)]$, an acetal carbon $\left[\delta_{\mathrm{C}} 111.2\right]$ and a quaternary oxygenated carbon $\left[\delta_{\mathrm{C}} 69.4\right]$ (Table 1). 
These data indicated that the aglycone of $\mathbf{1}$ was similar to the aglycone of jujuboside I (7) and suggested that $\mathbf{1}$ was a jujubogenin derivative (Wu et al., 2013). The only variation concerned the signal for $\mathrm{C}-7\left(\delta_{\mathrm{C}} 36.8\right)$ in 7 which was replaced by an oxygenated methine at $\delta_{\mathrm{C}} 76.0$ in 1 . The position of the hydroxyl group at $\mathrm{C}-7$ (B ring) was confirmed by the HMBC correlations observed between $\mathrm{H}_{3}$ 30 and $\mathrm{C}-7$ and between $\mathrm{H}-7$ and $\mathrm{C}-5$. In the ROESY spectrum, correlations observed between $\mathrm{H}-3 / \mathrm{H}-5, \mathrm{H}_{3}-28 / \mathrm{H}-$ $5, \mathrm{H}-5 / \mathrm{H}-9, \mathrm{H}-5 / \mathrm{H}-7$ and $\mathrm{H}-9 / \mathrm{H}-7$ confirmed the $\alpha$-axial orientation of these protons and the $\beta$ orientation of the hydroxyl group at C-7. Similarly, the cross-peaks, observed on the ROESY spectrum, between $\mathrm{H}_{3}-29 / \mathrm{H}_{3}-19$ and $\mathrm{H}_{3}$ $19 / \mathrm{H}_{3}-30$ confirmed the $\beta$-axial orientation of these methyl groups. The aglycone structure of $\mathbf{1}$ was assigned as $7 \beta$ hydroxy-jujubogenin on the basis of the ${ }^{1} \mathrm{H}$ and ${ }^{13} \mathrm{C}$ NMR spectra and correlations observed in COSY, HSQC and HMBC experiments. Most of the ${ }^{13} \mathrm{C}$ NMR signals were assigned through ${ }^{2} J_{\mathrm{H}-\mathrm{C}}$ and ${ }^{3} J_{\mathrm{H}-\mathrm{C}}$ couplings of the seven methyls and are in agreement with literature data except for the $\mathrm{B}$ ring (Table 1). The magnitude of the coupling constants between $\mathrm{H}-13$ and $\mathrm{H}-17(J=6.9 \mathrm{~Hz})$ and $\mathrm{H}-23(\beta)$ and $\mathrm{H}-22(\beta)(J=11.2 \mathrm{~Hz})$, and the ROESY correlations observed between $\mathrm{H}-17, \mathrm{H}_{3}-21$, and $\mathrm{H}-22(\alpha)$, between $\mathrm{H}-22$ $(\beta)$ and $\mathrm{H}-23$, and between $\mathrm{H}-13 / \mathrm{H}-15(\beta)$ and $\mathrm{H}-23 / \mathrm{H}-15$ $(\beta)$ are in agreement with the configuration of rings D-F of jujubogenin (Renault et al., 1997). The downfield shift of C$3\left(\delta_{\mathrm{C}} 90.1\right)$ suggested a monodesmosidic saponin. Analysis of the ${ }^{1} \mathrm{H}$ and ${ }^{13} \mathrm{C}$ NMR spectra of 1 revealed the presence of two anomeric protons at $\delta_{\mathrm{H}} 4.55$ and 5.12 correlated in the HSQC spectrum with the anomeric carbons at $\delta_{\mathrm{C}} 104.9$ and 102.0, respectively (Table 2). Starting from the anomeric proton at $\delta_{\mathrm{H}} 4.55(\mathrm{~d}, J=4.7 \mathrm{~Hz})$, the NMR signals belonging to the same system were assigned to a C-2 monosubstituted $\alpha$-L-arabinopyranose (ara) (Table 2) by interpretation of COSY, HSQC and HMBC spectra and by comparing the ${ }^{13} \mathrm{C}$ NMR chemical shifts with those of related systems reported in the literature (Alabdul Magid et al., 2015, Wu et al., 2013). The L-arabinopyranose unit was determined to be in an $\alpha$-configuration on the basis of the $J_{\mathrm{H} 1-\mathrm{H} 2}$ value $(4.7 \mathrm{~Hz})$ and this was confirmed by the observation of ROESY correlations between the $\alpha$-axial protons $\mathrm{H}-1 / \mathrm{H}-3$ and $\mathrm{H}-1 / \mathrm{H}-5$. The second sugar unit with its anomeric proton at $\delta_{\mathrm{H}} 5.12(\mathrm{~d}, J=1.5 \mathrm{~Hz})$ was identified as a terminal $\alpha$-L-rhamnopyranose (rha) with its methyl group at $\delta_{\mathrm{H} 6} 1.24(\mathrm{~d}, J=6.2 \mathrm{~Hz}$ ) (Table 2) (Alabdul Magid et al., 2015). The observed small coupling constant $\left(J_{\mathrm{H} 1, \mathrm{H} 2}\right)$ of the rhamnopyranose and the chemical shift of its C-5 $\left(\delta_{\mathrm{C}}\right.$ 70.2) indicated an $\alpha$ configuration (Backinowsky et al., 1980). The HMBC correlations observed between rha-H-1 and ara-C-2 indicated that the rhamnose residue was 2-Olinked to the arabinose unit, whereas the HMBC correlations between ara-H-1 and C-3 of aglycone showed that the diglycosidic chain [rha- $(1 \rightarrow 2)$-ara-] was linked to the aglycone at $\mathrm{C}-3$ position. Thus, the structure of $\mathbf{1}$ was established as $7 \beta$-hydroxy-jujubogenin-3- $O-\alpha$-Lrhamnopyranosyl- $(1 \rightarrow 2)-\alpha$-L-arabinopyranoside.
The molecular formula of gouaniaside II (2) was determined as $\mathrm{C}_{41} \mathrm{H}_{64} \mathrm{O}_{12}$ by HR-ESI-MS. The ${ }^{1} \mathrm{H}$ NMR spectrum of the aglycone of $\mathbf{2}$ displayed signals for seven methyl groups at $\delta_{\mathrm{H}} 0.83,1.16,1.75,1.73,1.04,0.97$, and 1.78 (all s, $\mathrm{H}_{3}-19, \mathrm{H}_{3}-21, \mathrm{H}_{3}-26, \mathrm{H}_{3}-27, \mathrm{H}_{3}-28, \mathrm{H}_{3}-29$ and $\mathrm{H}_{3}-30$ ), an oxygenated methine at $\delta_{\mathrm{H}} 3.15$ (dd, $J=11.8,3.8$ $\mathrm{Hz}, \mathrm{H}-3)$, an oxygenated methylene $\left(\delta_{\mathrm{H}} 3.40\right.$ and 4.23 (each $\left.\mathrm{d}, J=7.0 \mathrm{~Hz}, \mathrm{H}_{2}-18\right)$ and a vinyl proton at $\delta_{\mathrm{H}} 5.20(\mathrm{td}, J=$ 8.5,1.5 Hz, H-24). A comparison of the ${ }^{13} \mathrm{C}$ NMR spectra of 2 with that of 7 revealed a similar aglycone. The main difference was the presence of signals of a second double bond $\left(\delta_{\mathrm{C}} 128.3\right.$ and 130.2) (Table 1$)$. Its NMR spectroscopic data differed from those of compound 7 only in ring $\mathrm{B}$. The second double bond was placed at $\mathrm{C}-7 / \mathrm{C}-8$ as deduced from the HMBC correlations between $\mathrm{H}-9 / \mathrm{C}-8, \mathrm{H}-11 / \mathrm{C}-8$ and $\mathrm{H}-$ $13 / \mathrm{C}-8$ and between H-5/C-7 and H-9/C-7. $\mathrm{H}_{3}-30\left(\delta_{\mathrm{H}} 1.78\right.$, $\delta_{\mathrm{C}}$ 20.7) was located at C-7 as confirmed by HMBC correlations from $\mathrm{H}_{3}-30$ to $\mathrm{C}-5, \mathrm{C}-6, \mathrm{C}-7$ and $\mathrm{C}-8$. The relative configurations of methyl groups and the other asymmetric carbons were verified as in compound $\mathbf{1}$ by the ROESY correlations and were identical to those of jujubogenin. Thus, the aglycone of 2 was identified as 7methyl,7,8-didehydro,30-nor-jujubogenin. Furthermore, the NMR data suggested that $\mathbf{2}$ possessed the same sugar moieties as $\mathbf{1}$ and the linkages of sugar moieties were also established by analysis of the HMBC correlations. Thus, compound 2 was concluded to be 7-methyl,7,8didehydro,30-nor-jujubogenin-3-O- $\alpha$-L-rhamnopyranosyl$(1 \rightarrow 2)$ - $\alpha$-L-arabinopyranoside.

The molecular formula of gouaniaside III (3) was established as $\mathrm{C}_{47} \mathrm{H}_{74} \mathrm{O}_{17} \quad$ (HR-ESI-MS $\quad m / z \quad 933.4836$ $\left.[\mathrm{M}+\mathrm{Na}]^{+}\right)$. Comparison of the NMR data of compounds 2 and $\mathbf{3}$ indicated that they possessed the same aglycone but one supplementary sugar moiety in $\mathbf{3}$ (Tables 1 and 2). Analysis of COSY and HSQC spectra, allowed assignment of this supplementary monosaccharide as a terminal glucopyranose unit (glc), whose anomeric proton and carbon were assigned at $\delta_{\mathrm{H}} 4.52(\mathrm{~d}, J=7.7 \mathrm{~Hz})$ and $\delta_{\mathrm{C}} 104.3$. The deshielded signals of ara-C-3 $\left(\delta_{\mathrm{C}} 82.2\right)$ indicated that the additional glucopyranose moiety was attached to $\mathrm{C}-3$ of the arabinosyl unit. This was confirmed by the HMBC correlation between glc-H-1 $\left(\delta_{\mathrm{H}} 4.52\right)$ and ara-C-3 $\left(\delta_{\mathrm{C}} 82.2\right)$. Thus, the structure of $\mathbf{3}$ was elucidated as 7-methyl,7,8didehydro,30-nor-jujubogenin-3-O- $\beta$-D-glucopyranosyl$(1 \rightarrow 3)$-[ $\alpha$-L-rhamnopyranosyl- $(1 \rightarrow 2)]-\alpha$-Larabinopyranoside.

The positive HR-ESI-MS spectrum of gouaniaside IV (4) showed a pseudomolecular ion peak $[\mathrm{M}+\mathrm{Na}]+$ at $m / z 975.4918\left(\mathrm{C}_{49} \mathrm{H}_{76} \mathrm{O}_{18} \mathrm{Na}\right)$ suggesting the presence of a supplementary acetyl group (42 amu) compared to 3 . The ${ }^{1} \mathrm{H}$ and ${ }^{13} \mathrm{C}$ NMR data of $\mathbf{4}$ were closely comparable to those of 3 , except for the signals of the glucose moiety and the presence of signals for an acetyl group $\left(\delta_{\mathrm{H}} 2.08, \delta_{\mathrm{C}} 20.8\right.$, 172.7) (Table 2). The $\beta$-D-glucopyranose possessed two deshielded protons $\mathrm{H}_{2}-6$ at $\delta_{\mathrm{H}} 4.22$ and 4.44 , indicating the position of the acetyl group. This was readily confirmed by the HMBC correlation between glc- $\mathrm{H}_{2}-6$ and the carbonyl signal $\left(\delta_{\mathrm{C}} 172.7\right)$ of the acetyl group. Extensive elucidation 
of its $1 \mathrm{D}$ and 2D NMR data led to the structure of 4 as 7 methyl,7,8-didehydro,30-nor-jujubogenin-3-O-(6-O-acetyl-
$\beta$-D-glucopyranosyl-( $1 \rightarrow 3))$-[ $\alpha$-L-rhamnopyranosyl-( $(1 \rightarrow 2)]$ $\alpha$-L-arabinopyranoside.

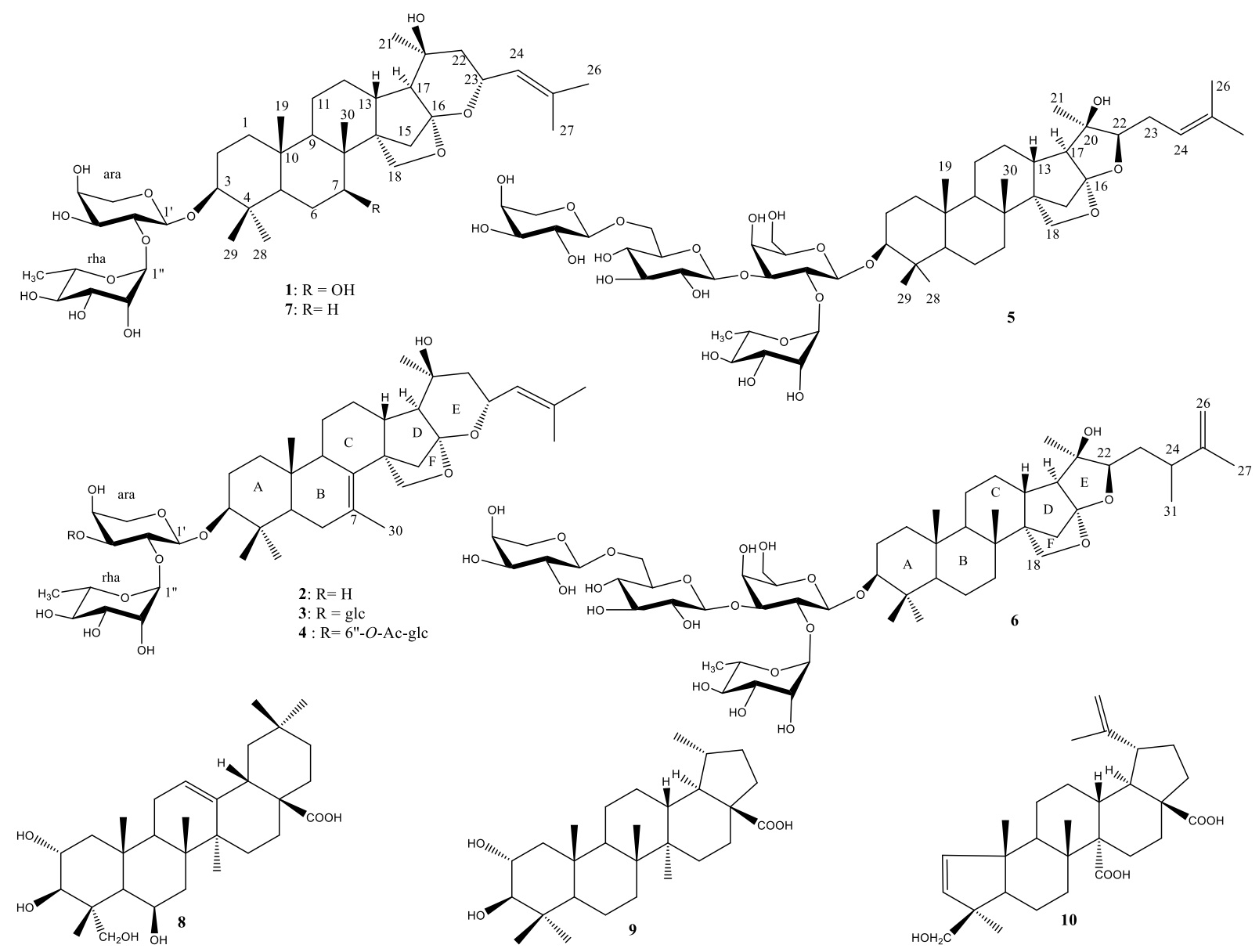

Figure 1. Chemical structures of triterpenes 1-10, isolated from the aerial parts of Gouania longipetala.

The molecular formula of gouaniaside $\mathrm{V}$ (5) was established as $\mathrm{C}_{53} \mathrm{H}_{86} \mathrm{O}_{22}$ by HR-ESI-MS $(\mathrm{m} / \mathrm{z} 1097.5519$ [M $\left.+\mathrm{Na}^{+}\right)$. The ${ }^{1} \mathrm{H}$ NMR spectrum of 5 displayed for the aglycone signals for seven methyl groups, an oxygenated methine $\left[\delta_{\mathrm{H}} 3.18(\mathrm{dd}, J=11.4,4.1 \mathrm{~Hz}, \mathrm{H}-3)\right]$, an oxygenated methylene [ $\delta_{\mathrm{H}} 3.95$ and3.97 (each d, $J=9.1 \mathrm{~Hz}, \mathrm{H}_{2}-18$ )], and a vinylic proton $\left[\delta_{\mathrm{H}} 5.22(\mathrm{t}, J=6.5 \mathrm{~Hz}, \mathrm{H}-24)\right]$ (Table 1). Full assignment of the ${ }^{13} \mathrm{C}$ NMR signals was achieved through ${ }^{2} J_{\mathrm{H}-\mathrm{C}}$ and ${ }^{3} J_{\mathrm{H}-\mathrm{C}}$ correlations in the HMBC spectra which allow the identification of the known aglycone (20R,22R)-16 $\beta, 22: 16 \alpha, 18$-diepoxydammar-24-ene-3 $\beta, 20$ -

diol (Maciuk et al, 2004, Yoshikawa et al., 1992). The terminal tetrahydrofuran ring structure was assumed on the basis of the deshielded acetal carbon C-16 at $\delta_{\mathrm{C}} 118.9$, of an oxygenated methine C-22 $\left(\delta_{\mathrm{C}} 95.5\right)$ correlated in the HSQC spectrum with a proton at $\delta_{\mathrm{H}} 4.14(\mathrm{brt}, J=6.5 \mathrm{~Hz})$, and of a methylene $\mathrm{C}-23\left(\delta_{\mathrm{C}} 28.7\right)$ reliable to two equivalent protons at $\delta_{\mathrm{H}} 2.30(\mathrm{t}, J=6.5 \mathrm{~Hz})$. The spatial ROE correlations between $\mathrm{H}_{3}-21 / \mathrm{H}-22$ and between $\mathrm{H}-17 / \mathrm{H}_{2}-18$ confirmed the configuration at C-16, C-20, and C-22 (Yoshikawa et al., 1992). The ${ }^{1} \mathrm{H}$ and ${ }^{13} \mathrm{C}-\mathrm{NMR}$ spectra revealed the presence of four sugar units with the anomeric carbons at $\delta_{\mathrm{C}} 105.9$, 105.4, 104.9, and 101.0 and the corresponding anomeric protons at $\delta_{\mathrm{H}} 4.44(\mathrm{~d}, J=7.0 \mathrm{~Hz}), 4.28(\mathrm{~d}, J=6.4 \mathrm{~Hz}), 4.52$ $(\mathrm{d}, J=7.0 \mathrm{~Hz})$ and $5.38(\mathrm{~d}, J=1.4 \mathrm{~Hz}$ ) (Table 2). Analysis of COSY, HSQC, and HMBC spectra allowed identification of a $\beta$-D-galactopyranosyl (gal) disubstituted at gal-C-2 and gal-C-3 positions, a terminal $\alpha$-L-arabinopyranosyl, a $\beta$-Dglucopyranosyl substituted at C-6 and a terminal $\alpha$-Lrhamnopyranosyl, respectively (Table 2). The HMBC correlations between gal-H-1/C-3 $\left(\delta_{\mathrm{C}} 89.9\right)$ of aglycone, rha$\mathrm{H}-1 /$ gal-C-2 $\left(\delta_{\mathrm{C}} 75.5\right)$, glc-H-1/gal-C-3 $\left(\delta_{\mathrm{C}} 85.6\right)$ and ara-H$1 /$ glc-C-6 $\left(\delta_{\mathrm{C}} 70.7\right)$ indicated that gouaniaside $\mathrm{V}(\mathbf{5})$ was $(20 R, 22 R)-16 \beta, 22: 16 \alpha, 18$-diepoxydammar-24-ene-3 $\beta, 20$ -

diol-3- $O$ - $(\alpha$-L-arabinopyranosyl-( $1 \rightarrow 6)-\beta$-D-glucopyranosyl$(1 \rightarrow 3)$-[ $\alpha$-L-rhamnopyranosyl- $(1 \rightarrow 2)]-\beta$-Dgalactopyranoside.

The molecular formula of gouaniaside VI (6) was established as $\mathrm{C}_{54} \mathrm{H}_{88} \mathrm{O}_{22}$ by HR-ESI-MS ( $\mathrm{m} / \mathrm{z} 1111.5669$ [M $+\mathrm{Na}]^{+}$, calcd for $\mathrm{C}_{54} \mathrm{H}_{88} \mathrm{O}_{22} \mathrm{Na}$ ). The ${ }^{1} \mathrm{H}$ NMR spectrum of 6 showed six singlets for six tertiary methyl groups at $\delta_{\mathrm{H}} 0.87$, $0.89,1.06,1.15,1.21$ and 1.66 , and a methyl doublet at $\delta_{\mathrm{H}}$ $1.06(J=2.8 \mathrm{~Hz}) \quad$ (Table 1$)$. The presence of two other doublets at $\delta_{\mathrm{H}} 4.74$ and 4.76 (each $J=1.0 \mathrm{~Hz}$ ) assigned to two exomethylene protons, suggested that $\mathbf{6}$ possessed an isopropyl side chain with terminal methylene, as observed with $\mathrm{C}_{31}$-type derivatives (Brandao et al., 1993). The ${ }^{1} \mathrm{H}$ NMR and ${ }^{13} \mathrm{C}$ NMR spectra of $\mathbf{6}$ showed signals superimposable to those of $\mathbf{5}$ except for the side chain suggesting a dammarane derivative possessing a $\mathrm{C}_{31}$ skeleton (Table 1) (Brandao et al., 1993, Perera et al., 1993). The COSY correlations between H-22/H-23, H-23/H-24 and 
$\mathrm{H}-24 / \mathrm{H}-31$ indicated that $\mathrm{CH}_{3}-31$ was located at $\mathrm{C}-24$. This was confirmed by the $\mathrm{HMBC}$ correlations between the protons of $\mathrm{CH}_{3}-31$ and the carbons $\mathrm{C}-23, \mathrm{C}-24$, and $\mathrm{C}-25$. On the other hand, the signal at $\delta_{\mathrm{C}} 111.2$ from the exomethylene group was assigned at $\mathrm{C}-26$ as deduced from the HMBC correlations between the methylene protons and carbons C-24 and C-26 and between the protons of $\mathrm{CH}_{3}-27$ and carbons C-24, C-25, and C-26. The stereochemical assignments were fully validated by analysis of ROESY spectra and the aglycone of $\mathbf{6}$ was concluded to be
(20R,22R)-16 $\beta, 22: 16 \alpha, 18$-diepoxydammar-31-methyl25(26)-methylene-3 $\beta, 20$-diol (Perera et al., 1993). Analysis of $1 \mathrm{D}$ and 2- NMR data suggested that 6 possessed the same tetrasaccharide chain as $\mathbf{5}$ attached to the aglycone at C-3 position $\left(\delta_{\mathrm{C}} 89.9\right)$ (Table 2$)$. Therefore, the structure of gouaniaside VI (6) was determined as $(20 R, 22 R)$ 16 $\beta, 22: 16 \alpha, 18$-diepoxydammar-31-methyl-25(26)methylene-3 $\beta, 20$-diol-3- $O$ - $(\alpha$-L-arabinopyranosyl- $(1 \rightarrow 6)-\beta$ D-glucopyranosyl-( $1 \rightarrow 3)$-[ $\alpha$-L-rhamnopyranosyl- $(1 \rightarrow 2)]-\beta$ D-galactopyranoside.

Table 1. ${ }^{1} \mathrm{H}$ and ${ }^{13} \mathrm{C}$ NMR data of the aglycone moieties of compounds 1-7 (in $\mathrm{CD}_{3} \mathrm{OD}$ ).

\begin{tabular}{|c|c|c|c|c|c|c|c|c|c|c|c|c|c|c|}
\hline & 1 & & 2 & & 3 & & 4 & & 5 & & 6 & & 7 & \\
\hline & $\delta_{\mathrm{H}} \mathrm{m}(J \mathrm{in} \mathrm{Hz})$ & $\delta$ & $\delta_{\mathrm{H}} \mathrm{m}(J \mathrm{in} \mathrm{Hz})$ & $\delta_{c}$ & $\delta_{\mathrm{H}} \mathrm{m}(J$ in $\mathrm{Hz})$ & $\delta$ & $\delta_{\mathrm{H}} \mathrm{m}(J$ in $\mathrm{Hz})$ & $\delta_{c}$ & $\delta_{\mathrm{H}} \mathrm{m}(J$ in $\mathrm{Hz})$ & $\delta_{c}$ & & & $\delta_{\mathrm{H}} \mathrm{m}(J$ in $\mathrm{Hz})$ & $\delta_{0}$ \\
\hline 1 & $0.94 \mathrm{dd}(13.9,4.0)$ & 39.6 & $1.16 \mathrm{~m}$ & 39.6 & $1.12 \mathrm{~m}$ & 39.7 & $1.16 \mathrm{brd}(4.5)$ & 39.8 & $0.96 \mathrm{~m}$ & 40.1 & $0.99 \mathrm{~m}$ & 40.1 & $0.98 \mathrm{dd}(14.4,4.1)$ & 39.8 \\
\hline & $1.72 \mathrm{~m}$ & & $1.88 \mathrm{~m}$ & & $1.87 \mathrm{~m}$ & & $1.88 \mathrm{~m}$ & & $1.70 \mathrm{~m}$ & & $1.71 \mathrm{~m}$ & & $1.72 \mathrm{~m}$ & \\
\hline 2 & $1.67 \mathrm{~m}$ & 29.3 & $1.70 \mathrm{~m}$ & 27.3 & $1.67 \mathrm{~m}$ & 27.5 & $1.69 \mathrm{~m}$ & 27.5 & $1.67 \mathrm{~m}$ & 27.4 & $1.70 \mathrm{~m}$ & 27.4 & $1.73 \mathrm{~m}$ & 27.1 \\
\hline & $1.87 \mathrm{~m}$ & & $1.87 \mathrm{~m}$ & & $1.85 \mathrm{~m}$ & & $1.84 \mathrm{~m}$ & & $1.95 \mathrm{~m}$ & & $1.95 \mathrm{~m}$ & & $1.86 \mathrm{~m}$ & \\
\hline 3 & $3.13 \mathrm{dd}(12.1,4.8)$ & 90.1 & $3.15 \mathrm{dd}(11.8,3.8)$ & 90.5 & $3.18 \mathrm{dd}(11.8,3.8)$ & 89.7 & $3.20 \mathrm{dd}(11.8,3.8)$ & 89.5 & $\begin{array}{lll}3.18 & \text { dd } & (11.4, \\
4.1)\end{array}$ & 89.9 & $\begin{array}{l}3.18 \text { dd } \quad(11.6, \\
4.2)\end{array}$ & 89.9 & 3.12 (dd. 11.4, 4.3) & 90.4 \\
\hline 4 & & 40.2 & & 39.7 & & 39.8 & & 40.1 & & 40.4 & & 40.5 & & 40.5 \\
\hline 5 & $0.86 \mathrm{brd}(12.7)$ & 54.7 & $1.07 \mathrm{~m}$ & 51.0 & $1.05 \mathrm{~m}$ & 51.1 & $1.05 \mathrm{dd}(13.3,2.4)$ & 51.1 & $0.75 \mathrm{~m}$ & 57.6 & $0.76 \mathrm{~m}$ & 57.7 & $0.77 \mathrm{brd}(11.4)$ & 57.3 \\
\hline \multirow[t]{2}{*}{6} & $1.60 \mathrm{brt}(12.7)$ & 22.4 & $1.84 \mathrm{~m}$ & 32.8 & $1.83 \mathrm{~m}$ & 32.8 & $1.82 \mathrm{~m}$ & 32.7 & $1.50 \mathrm{~m}$ & 19.1 & $1.55 \mathrm{~m}$ & 19.1 & $1.55 \mathrm{~m}$ & 19.2 \\
\hline & $1.66 \mathrm{~m}$ & & $2.04 \mathrm{~m}$ & & $2.02 \mathrm{~m}$ & & $2.03 \mathrm{~m}$ & & $1.63 \mathrm{~m}$ & & $\begin{array}{l}1.60 \text { dd } \quad(11.3, \\
5.4)\end{array}$ & & $1.58 \mathrm{~m}$ & \\
\hline 7 & $3.68 \mathrm{dd}(12.7,3.4)$ & 76.0 & & 130.2 & & 130.2 & & 130.2 & $1.50 \mathrm{~m}$ & 36.9 & $1.50 \mathrm{~m}$ & 37.0 & $1.50 \mathrm{~m}$ & 36.8 \\
\hline & & & & & & & & & $1.55 \mathrm{~m}$ & & $1.55 \mathrm{~m}$ & & $1.56 \mathrm{~m}$ & \\
\hline 8 & & 44.4 & & 128.3 & $1.67 \mathrm{~m}$ & 128.3 & $1.67 \mathrm{~m}$ & 128.2 & & 38.7 & & 38.7 & & 38.5 \\
\hline 9 & $0.87 \mathrm{~m}$ & 53.0 & $1.67 \mathrm{~m}$ & 52.9 & & 53.0 & & 53.0 & $0.77 \mathrm{~m}$ & 53.8 & $0.78 \mathrm{~m}$ & 53.8 & $0.91 \mathrm{~m}$ & 54.1 \\
\hline 10 & & 38.0 & & 36.2 & & 36.2 & $1.28 \mathrm{~m}$ & 36.2 & & 38.1 & & 38.2 & & 38.3 \\
\hline \multirow[t]{2}{*}{11} & $1.60 \mathrm{brt}(12.1)$ & 29.0 & $1.28 \mathrm{~m}$ & 27.9 & $1.28 \mathrm{~m}$ & 27.9 & $1.67 \mathrm{~m}$ & 27.9 & $1.48 \mathrm{~m}$ & 22.2 & $1.49 \mathrm{~m}$ & 22.2 & $1.51 \mathrm{~m}$ & 22.5 \\
\hline & $1.66 \mathrm{~m}$ & & $1.82 \mathrm{~m}$ & & $1.67 \mathrm{~m}$ & & $1.75 \mathrm{~m}$ & & $1.60 \mathrm{~m}$ & & $1.63 \mathrm{~m}$ & & $1.66 \mathrm{brd}(12.6)$ & \\
\hline \multirow[t]{2}{*}{12} & $1.72 \mathrm{~m}$ & 27.2 & $1.75 \mathrm{~m}$ & 29.0 & $1.82 \mathrm{~m}$ & 29.0 & $1.87 \mathrm{~m}$ & 29.0 & $1.65 \mathrm{~m}$ & 28.3 & $1.66 \mathrm{~m}$ & 28.3 & $1.70 \mathrm{~m}$ & 29.2 \\
\hline & $1.88 \mathrm{~m}$ & & $1.88 \mathrm{~m}$ & & $1.87 \mathrm{~m}$ & & $2.17 \mathrm{~m}$ & & $1.89 \mathrm{~m}$ & & $1.90 \mathrm{~m}$ & & $1.87 \mathrm{~m}$ & \\
\hline 13 & $2.45 \mathrm{~m}$ & 38.8 & $2.17 \mathrm{~m}$ & 44.2 & $2.17 \mathrm{~m}$ & 44.2 & & 44.2 & $2.43 \mathrm{~m}$ & 38.2 & $2.43 \mathrm{~m}$ & 38.2 & 2.51 brt (6.4) & 38.1 \\
\hline$\frac{13}{14}$ & & $\begin{array}{l}3.6 \\
53.3 \\
\end{array}$ & & 51.4 & & 51.4 & & 51.4 & & $\frac{50.2}{57.5}$ & & $\frac{50.2}{57.6}$ & & 54.6 \\
\hline \multirow[t]{2}{*}{15} & $1.65 \mathrm{~d}(9.3)$ & 40.7 & $1.88 \mathrm{~d}(8.7)$ & 44.6 & $1.89 \mathrm{~d}(8.6)$ & 44.6 & $1.89 \mathrm{~d}(8.6)$ & 44.6 & $1.41 \mathrm{~d}(9.0)$ & 38.9 & $1.42 \mathrm{dd}(8.1,5.4)$ & 38.9 & $1.21 \mathrm{dd}(8.6,1.2)$ & 37.1 \\
\hline & $2.25 \mathrm{~d}(9.3)$ & & $2.65 \mathrm{~d}(8.7)$ & & $2.65 \mathrm{~d}(8.6)$ & & $2.65 \mathrm{~d}(8.6)$ & & $1.68 \mathrm{~d}(9.0)$ & & $1.68 \mathrm{brd}(5.7)$ & & $2.08 \mathrm{~d}(8.6)$ & \\
\hline 16 & & 111.2 & & 112.1 & & 112.1 & & 112.0 & & 118.9 & & 119.2 & & 111.4 \\
\hline 17 & $0.98 \mathrm{dd}(6.9,1.8)$ & 53.6 & $1.06 \mathrm{~m}$ & 53.4 & $1.06 \mathrm{~d}(4.3)$ & 53.4 & $1.05 \mathrm{~d}(4.3)$ & 53.4 & $1.81 \mathrm{~d}(7.2)$ & 62.9 & $1.81 \mathrm{~d}(7.1)$ & 62.9 & $1.02 \mathrm{~m}$ & 54.4 \\
\hline 18 & $4.02 \mathrm{~d}(7.2)$ & 66.9 & $3.40 \mathrm{~d}(7.5)$ & 72.8 & $4.23 \mathrm{~d}(7.0)$ & 72.8 & $4.23 \mathrm{~d}(7.0)$ & 72.8 & $3.95 \mathrm{~d}(9.1)$ & 66.8 & $3.94 \mathrm{~d}(9.7)$ & 66.7 & $3.96 \mathrm{dd}(7.5,1.4)$ & 66.9 \\
\hline & $4.06 \mathrm{~d}(7.2)$ & & $4.23 \mathrm{~d}(7.0)$ & & $3.40 \mathrm{~d}(7.0)$ & & $3.40 \mathrm{~d}(7.0)$ & & $3.97 \mathrm{~d}(9.1)$ & & $3.96 \mathrm{~d}(9.7)$ & & $4.05 \mathrm{~d}(7.5)$ & \\
\hline 19 & $0.89 \mathrm{~s}$ & 16.5 & $0.83 \mathrm{~m}$ & 15.3 & $\frac{3.40 \mathrm{a}(1.0)}{0.83 \mathrm{~s}}$ & 15.3 & $\frac{3.40 \mathrm{~s}}{0.83 \mathrm{~s}}$ & 15.3 & $0.89 \mathrm{~s}$ & 17 & $0.89 \mathrm{~s}$ & 16.9 & $0.91 \mathrm{~s}$ & 16.8 \\
\hline 20 & & 69.4 & & 69.2 & & 69.2 & & 69.2 & & 76.5 & & 76.6 & & 69.4 \\
\hline 21 & $1.16 \mathrm{~s}$ & 29.7 & $1.16 \mathrm{~s}$ & 29.5 & $1.17 \mathrm{~s}$ & 29.5 & $1.17 \mathrm{~s}$ & 29.6 & $1.20 \mathrm{~s}$ & 23.5 & $1.21 \mathrm{~s}$ & 23.4 & $1.16 \mathrm{~s}$ & 29.6 \\
\hline \multirow[t]{2}{*}{22} & $1.40 \mathrm{dd}(13.9,11.2)$ & 45.4 & $1.41 \mathrm{dd}(13.9,11.1)$ & 45.2 & $\begin{array}{lll}1.41 & \text { dd } & (13.2, \\
11.1) & \end{array}$ & 45.2 & $\begin{array}{lll}1.41 & \text { dd } & (13.2, \\
11.1) & \end{array}$ & 45.2 & $4.14 \mathrm{t}(6.5)$ & 95.5 & $4.34 \mathrm{dd}(9.8,3.0)$ & 94.0 & $1.40 \mathrm{dd}(13.7,11.2)$ & 45.4 \\
\hline & $1.49 \mathrm{dd}(13.9,1.6)$ & & $1.51 \mathrm{dd}(13.9,2.1)$ & & $1.51 \mathrm{dd}(13.2,2.1)$ & & $1.50 \mathrm{dd}(13.2,2.1)$ & & & & & & $1.49 \mathrm{dd}(11.2,1.5)$ & \\
\hline \multirow[t]{2}{*}{23} & $\begin{array}{l}4.70 \text { ddd }(11.2,8.6 \\
1.6)\end{array}$ & 69.6 & 4.76 ddd $(11.1,8.5$, & 69.9 & $\begin{array}{l}4.76 \\
8.3\end{array}$ brdd $\quad$ (11.1, & 69.9 & $\begin{array}{l}4.76 \text { brdd } \quad \text { (11.1, } \\
8.3\end{array}$ & 69.9 & $2.30 \mathrm{t}(6.5)$ & 28.7 & $\begin{array}{l}1.59 \text { dd } \quad(11.3, \\
9.8)\end{array}$ & 34.7 & $\begin{array}{l}4.70 \text { ddd }(11.2,8.6 \text {, } \\
1.5)\end{array}$ & 69.7 \\
\hline & & & & & & & & & & & $\begin{array}{lll}2.33 & \text { dd } & (11.3, \\
3.0) & & \\
\end{array}$ & & & \\
\hline 24 & $5.18 \operatorname{td}(8.6,1.5)$ & 126.3 & $5.20 \operatorname{td}(8.5,1.5)$ & 126.3 & $5.20 \operatorname{td}(8.3,1.4)$ & 126.3 & $5.20 \operatorname{td}(8.3,1.4)$ & 126.3 & $5.22 \mathrm{brt}(6.5)$ & 122.1 & $2.42 \mathrm{~m}$ & 39.6 & $5.18 \operatorname{td}(8.6,1.5)$ & 126.3 \\
\hline 25 & & 136.8 & & 136.8 & & 136.8 & & 136.8 & & 134.0 & & 150.0 & & 136.7 \\
\hline 26 & $1.74 \mathrm{~d}(1.0)$ & 25.8 & $1.75 \mathrm{~d}(1.2)$ & 25.8 & $1.75 \mathrm{~d}(1.4)$ & 25.8 & $1.75 \mathrm{~d}(1.2)$ & 25.8 & $1.70 \mathrm{~m}$ & 25.9 & $4.74 \mathrm{~d}(1.0)$ & 111.2 & $1.74 \mathrm{~m}$ & 25.8 \\
\hline & & & & & & & & & & & $4.76, \mathrm{~d}(1.0)$ & & & \\
\hline 27 & $1.71 \mathrm{~d}(1.1)$ & 18.4 & $1.73 \mathrm{~d}(1.3)$ & 18.4 & $1.73 \mathrm{~d}(1.4)$ & 18.4 & $1.73 \mathrm{~d}(1.2)$ & 18.4 & $1.66 \mathrm{~m}$ & 17.9 & $1.66 \mathrm{~m}$ & 18.8 & $1.71 \mathrm{~s}$ & 18.4 \\
\hline 28 & $1.04 \mathrm{~s}$ & 28.5 & $1.04 \mathrm{~s}$ & 28.8 & $1.05 \mathrm{~s}$ & 28.8 & $1.05 \mathrm{~s}$ & 28.9 & $1.06 \mathrm{~s}$ & 28.4 & $1.06 \mathrm{~s}$ & 28.4 & $1.02 \mathrm{~s}$ & 28.5 \\
\hline 29 & $0.87 \mathrm{~s}$ & 16.8 & $0.97 \mathrm{~s}$ & 17.1 & $0.98 \mathrm{~s}$ & 17.2 & $0.98 \mathrm{~s}$ & 17.2 & $0.87 \mathrm{~s}$ & 16.9 & $0.87 \mathrm{~s}$ & 17.0 & $0.86 \mathrm{~s}$ & 16.9 \\
\hline 30 & $1.15 \mathrm{~s}$ & 13.4 & $1.78 \mathrm{~m}$ & 20.7 & $1.78 \mathrm{~s}$ & 20.7 & $1.78 \mathrm{~s}$ & 20.7 & $1.15 \mathrm{~s}$ & 19.2 & $1.15 \mathrm{~s}$ & 19.2 & $1.16 \mathrm{~s}$ & 19.2 \\
\hline 30 & $1.15 \mathrm{~s}$ & 13.4 & $1.78 \mathrm{~m}$ & 20.7 & $1.78 \mathrm{~s}$ & 20.7 & $1.78 \mathrm{~s}$ & 20.7 & $1.15 \mathrm{~s}$ & 19.2 & $1.15 \mathrm{~s}$ & 19.2 & $1.16 \mathrm{~s}$ & 19.2 \\
\hline 31 & & & & & & & & & & & $1.06 \mathrm{~d}(2.8)$ & 22.1 & & \\
\hline 30 & $1.15 \mathrm{~s}$ & 13.4 & $1.78 \mathrm{~s}$ & 20.7 & $1.78 \mathrm{~s}$ & 20.7 & $1.78 \mathrm{~s}$ & 20.7 & $1.15 \mathrm{~s}$ & 19.2 & $1.15 \mathrm{~s}$ & 19.2 & $1.16 \mathrm{~s}$ & 19.2 \\
\hline
\end{tabular}

Table 2. ${ }^{1} \mathrm{H}$ and ${ }^{13} \mathrm{C}$ NMR data of the sugar moieties of compounds 1 - $7\left(\mathrm{CD}_{3} \mathrm{OD}\right)$.

\begin{tabular}{|c|c|c|c|c|c|c|c|c|c|c|c|c|c|c|}
\hline & 1 & & 2 & & 3 & & 4 & & 5 & & 6 & & 7 & \\
\hline & $\delta_{\mathrm{f}} \mathrm{m}(J \mathrm{in} \mathrm{Hz})$ & $\delta$ & $\delta_{\mathrm{H}} \mathrm{m}(J \mathrm{in} \mathrm{Hz})$ & $\delta_{\mathrm{c}}$ & $\delta_{\mathrm{H}} \mathrm{m}(J$ in $\mathrm{Hz})$ & $\delta$ & & & & & & & $\delta_{\mathrm{H}} \mathrm{m}(J \mathrm{in} \mathrm{Hz})$ & $\delta$ \\
\hline \begin{tabular}{|c|}
$\alpha$-L-ara \\
\end{tabular} & & & & & & & & & & & & & & \\
\hline \begin{tabular}{|l|l|}
1 \\
\end{tabular} & $4.55 \mathrm{~d}(4.7)$ & 104.9 & $4.56 \mathrm{~d}(4.7)$ & $\begin{array}{l}104.8 \\
07.8\end{array}$ & $4.51 \mathrm{~d}(5.0)$ & 105.1 & $4.48 \mathrm{~d}(5.9)$ & 105.3 & $4.28 \mathrm{~d}(6.4)$ & 105.4 & $4.28 \mathrm{~d}(6.4)$ & 105.3 & $4.56 \mathrm{~d}(4.7)$ & 104.8 \\
\hline 2 & $3.78 \mathrm{dd}(6.7,4.7)$ & 76.9 & $3.79 \mathrm{dd}(6.6,4.7)$ & 77.0 & $3.90 \mathrm{dd}(7.3,5.0)$ & 75.4 & $3.89 \mathrm{dd}(7.7,5.7)$ & 75.4 & $3.58 \mathrm{t}(6.4)$ & 72.4 & $3.59 \mathrm{t}(6.4)$ & 72.4 & $3.79 \mathrm{dd}(6.6,4.7)$ & 76.9 \\
\hline$\frac{3}{4}$ & $\frac{3.75 \mathrm{dd}(6.7,3.3)}{3.80 \mathrm{~d}(6.1 .29)}$ & $\frac{73.2}{66.5}$ & $\frac{3.75 \mathrm{dd}(6.6,3.2)}{3.80 \mathrm{~m}}$ & $\frac{73.1}{68.5}$ & $\frac{3.89 \mathrm{dd}(7.3,2.4)}{4.05 \mathrm{st}(4 ., 24)}$ & $\begin{array}{l}82.2 \\
686 \\
\end{array}$ & $3.83 \mathrm{dd}(7.7,3.3)$ & 82.6 & $3.57 \mathrm{dd}(6.4,3.0)$ & $\begin{array}{ll}74.1 \\
695\end{array}$ & $3.58 \mathrm{dd}(6.4,3.2)$ & 74.1 & $3.75 \mathrm{dd}(6.6,3.3)$ & 73.1 \\
\hline$\frac{4}{5}$ & $\begin{array}{l}3.80 \mathrm{dd}(6.1,2.9) \\
3.5 \mathrm{dd}(1 ., 5,2.9\end{array}$ & 68.5 & $3.80 \mathrm{~m}$ & $\frac{68.5}{63.9}$ & $\begin{array}{l}3.0 .5 \mathrm{dt}(4.8,2.4) \\
3.35 \mathrm{dd}(12.12 .4)\end{array}$ & 68.6 & $\begin{array}{l}4.00 \mathrm{~m} \\
3.52 \mathrm{dd}(12.2 .2 .4)\end{array}$ & $\frac{68.8}{65.0}$ & $\frac{3.83 \mathrm{t}(3.0)}{3.56 \mathrm{~b} d(12.4)}$ & $\frac{69.5}{66.8}$ & $\frac{3.83 \mathrm{t}(3.2)}{3.57 \mathrm{brd}(12.4)}$ & 69.5 & $\begin{array}{l}3.80 \mathrm{ord}(3.0) \\
3.5 \mathrm{dd}(11.6,3.0)\end{array}$ & $\begin{array}{l}68.4 \\
63.8\end{array}$ \\
\hline & $3.85 \mathrm{dd}(11.5,6.1)$ & & $3.85 \mathrm{dd}(11.8,6.0)$ & & $3.89 \mathrm{dd}(12.1,4.8)$ & & $3.89 \mathrm{dd}(12.9,3.7$ & & $3.87 \mathrm{dd}(12.4,3.1)$ & & $3.88 \mathrm{~m}$ & & $3.85 \mathrm{dd}(11.6,6.6)$ & \\
\hline$\alpha$-L-rha & & & & & & & & & & & & & & \\
\hline & $5.12 \mathrm{~d}(1.5)$ & 102.0 & $5.13 \mathrm{brs}$ & 102.1 & $5.24 \mathrm{~d}(1.4)$ & 102.0 & $5.23 \mathrm{~d}(1.8)$ & 102.1 & $5.38 \mathrm{~d}(1.4)$ & 101.0 & $5.38 \mathrm{~d}(1.4)$ & 102.0 & $5.12 \mathrm{~d}(1.5)$ & 102.1 \\
\hline 2 & $3.90 \mathrm{dd}(3.4,1.7)$ & 72.2 & & $\frac{10.1}{72.2}$ & & 72.1 & & 72.1 & & & $3.99 \mathrm{dd}(3.2,1.4)$ & & & 102.1 \\
\hline 3 & $3.71 \mathrm{dd}(9.6 .6 .4)$ & 72.1 & $3.71 \mathrm{dd}(9.7,3.4)$ & 72.2 & $3.74 \mathrm{dd}(9.6 .3 .5)$ & 72.1 & $3.74 \mathrm{dd}(9.5,3.4)$ & 72.1 & $3.78 \mathrm{dd}(9.6 .3 .2)$ & 72.0 & $3.78 \mathrm{dd}(9.5,3.2)$ & $\frac{2.1}{72.1}$ & $3.71 \mathrm{dd}(9.6 .3 .4)$ & 72.2 \\
\hline 4 & $3.40 \mathrm{t}(9.5)$ & 73.9 & $3.40 \mathrm{t}(9.7)$ & 73.9 & $3.42 \mathrm{t}(9.6)$ & 73.8 & $3.41 \mathrm{t}(9.5)$ & 73.8 & $3.41 \mathrm{t}(9.6)$ & 73.8 & $3.41 \mathrm{t}(9.5)$ & 73.9 & $3.40 \mathrm{t}(9.5)$ & 73.9 \\
\hline 5 & $3.82 \mathrm{~m}$ & 70.2 & $3.82 \mathrm{~m}$ & 70.2 & $3.89 \mathrm{~m}$ & 70.3 & $3.89 \mathrm{~m}$ & 70.3 & $4.01 \mathrm{~m}$ & 70.1 & $4.01 \mathrm{~m}$ & 70.1 & $3.82 \mathrm{~m}$ & 70.2 \\
\hline 6 & $1.24 \mathrm{~d}(6.2)$ & 18.0 & $1.24 \mathrm{~d}(6.2)$ & 18.0 & $1.24 \mathrm{~d}(6.2)$ & 18.0 & $1.24 \mathrm{~d}(6.3)$ & 18.0 & $1.22 \mathrm{~d}(6.2)$ & 18.0 & $1.22 \mathrm{~d}(6.2)$ & 18.0 & $1.24 \mathrm{~d}(6.2)$ & 18.0 \\
\hline$\beta$-D-glc & & & & & $4.52 \mathrm{~d}(7.7)$ & 104.3 & $4.53 \mathrm{~d}(7.5)$ & 104.3 & $4.52 \mathrm{~d}(7.0)$ & 104.9 & $4.52 \mathrm{~d}(7.0)$ & 104.9 & & \\
\hline & & & & & $3.32 \mathrm{dd}(8.5,7.7)$ & $\frac{104.0}{75.0}$ & $3.33 \mathrm{dd}(8.1,7.5)$ & 74.9 & $3.33 \mathrm{dd}(9.5,7.0)$ & 75.1 & $\frac{3.32 \mathrm{btr}(9.7)}{3.32)}$ & 75.1 & & \\
\hline$\frac{1}{2}$ & & & & & $3.41 \mathrm{t}(8.5)$ & 78.0 & $3.40 \mathrm{t}(8.1)$ & 77.9 & $3.38 \mathrm{t}(9.5)$ & 78.2 & $3.37 \mathrm{t}(9.7)$ & 78.2 & & \\
\hline 3 & & & & & $3.37 \mathrm{t}(8.5)$ & 71.2 & $3.33 \mathrm{t}(8.1)$ & 71.6 & $3.28 \mathrm{t}(9.5)$ & 71.8 & $3.28 \mathrm{t}(9.7)$ & 71.9 & & \\
\hline 4 & & & & & $3.34 \mathrm{~m}$ & 78.0 & $3.53 \mathrm{~m}$ & 75.5 & 3.53 brt (9.5) & 76.8 & $3.52 \mathrm{~m}$ & 76.8 & & \\
\hline 5 & & & & & $3.70 \mathrm{dd}(11.8,4.9)$ & 62.4 & $4.22 \mathrm{dd}(12.0,6.4)$ & 64.6 & 3.66 dd $(11.3,7.3)$ & 70.7 & $3.66 \mathrm{dd}(11.3,7.3)$ & 70.2 & & \\
\hline 6 & & & & & $3.86 \mathrm{dd}(11.8,2.0)$ & & $4.44 \mathrm{dd}(12.0,2.3)$ & & $4.14 \mathrm{~m}$ & & $4.14 \mathrm{~m}$ & & & \\
\hline \begin{tabular}{|l|} 
Acetate \\
$\mathrm{CH}_{3}$
\end{tabular} & & & & & & & $2.08 \mathrm{~s}$ & 20.8 & & & & & & \\
\hline $\mathrm{CO}$ & & & & & & & & 172.7 & & & & & & \\
\hline$\beta$-D-gal & & & & & & & & & & & & & & \\
\hline$r$ & & & & & & & & & $4.44 \mathrm{~d}(7.0)$ & $\begin{array}{l}105.9 \\
75 .\end{array}$ & $4.44 \mathrm{~d}(7.0)$ & $\begin{array}{l}105.9 \\
757\end{array}$ & & \\
\hline$\frac{2}{3}$ & & & & & & & & & $3.82 \mathrm{dd}(7.4,7.0)$ & 7556 & $\frac{3.826 \mathrm{brt}(8.4)}{3.82 \mathrm{~m}}$ & $\frac{75.7}{85.7}$ & & \\
\hline 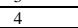 & & & & & & & & & $4.17 \mathrm{~d}(3.4)$ & $\frac{30.0}{70.0}$ & $\frac{3.17 \mathrm{~d}(3.2)}{4.13}$ & $\frac{10}{70.0}$ & & \\
\hline 5 & & & & & & & & & $3.58 \mathrm{~m}$ & 75.6 & $3.58 \mathrm{~m}$ & 75.7 & & \\
\hline 6 & & & & & & & & & $3.72 \mathrm{dd}(11.1,6.4)$ & 62.2 & $3.72 \mathrm{dd}(11.1,6.1)$ & 62.2 & & \\
\hline & & & & & & & & & & & & & & \\
\hline
\end{tabular}


Compounds 1-10 were evaluated for their effects on promyelocytic leukemia HL60 and human erythromyeloblastoid leukemia K562 cell lines with camptothecin as the positive control (Table 3). It was found that only jujuboside I (7) showed a moderate cytotoxicity, with $\mathrm{IC}_{50}$ value of $13.5 \mu \mathrm{M}$. In addition, the antibacterial

Table 3. Antimicrobial and cytotoxic activities of compounds 1-10. ${ }^{\mathrm{a} b}$ activity of these compounds was evaluated against Staphylococcus aureus, Escherichia coli and Enterococcus faecalis and only alphitolic acid (9) was found to exhibit significant inhibitory activity against $S$. aureus, E. faecalis and E. coli with MIC of $32 \mu \mathrm{g} / \mathrm{mL}, 64 \mu \mathrm{g} / \mathrm{mL}$ and 128 $\mu \mathrm{g} / \mathrm{mL}$ respectively (Table 3 ).

\begin{tabular}{|c|c|c|c|c|c|}
\hline \multirow[b]{2}{*}{ Compound } & \multicolumn{3}{|c|}{$\mathrm{MIC}(\mu \mathrm{g} / \mathrm{mL})$} & \multicolumn{2}{|c|}{ Anti-proliferative activity $(\mu \mathrm{M})$} \\
\hline & $\begin{array}{c}\text { S. aureus } \\
\text { (CIP53154) }\end{array}$ & $\begin{array}{c}\text { E. coli } \\
(\mathrm{DH} 5-\alpha)\end{array}$ & $\begin{array}{c}\text { E. faecalis } \\
\text { (ATCC 1054) }\end{array}$ & $\begin{array}{l}\text { HL60 } \\
\left(\mathrm{IC}_{50}\right) \\
\end{array}$ & $\begin{array}{l}\mathrm{K} 562 \\
\left(\mathrm{IC}_{50}\right) \\
\end{array}$ \\
\hline 7 & $-{ }^{\mathrm{a}}$ & $-^{\mathrm{a}}$ & $-{ }^{\mathrm{a}}$ & $13.5 \pm 0.12$ & $13.5 \pm 0.11$ \\
\hline 9 & 32 & 128 & 64 & $-\mathrm{b}$ & $-{ }^{b}$ \\
\hline Camptothecin ${ }^{\mathrm{c}}$ & - & - & - & $0.25 \pm 0.03$ & $0.30 \pm 0.05$ \\
\hline Gentamicin $^{c}$ & 0.5 & 0.5 & 0.5 & & \\
\hline
\end{tabular}

${ }^{\mathrm{a}}$ No microbial growth inhibition at $512 \mu \mathrm{g} / \mathrm{mL}$ for compounds 1-6 and 8-10.

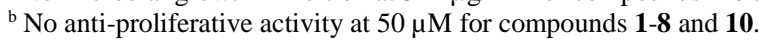

${ }^{\mathrm{c}}$ Used as positive controls.

\section{Experimental}

\subsection{General experimental procedures}

NMR spectra were carried in $\mathrm{CD}_{3} \mathrm{OD}$ on Bruker Avance DRX III 500 instruments $\left({ }^{1} \mathrm{H}\right.$ at $500 \mathrm{MHz}$ and ${ }^{13} \mathrm{C}-J \bmod$ at $125 \mathrm{MHz}$ ). HR-ESI-MS experiments were performed using a Micromass Q-TOF micro instrument (Manchester, UK) equipped with an electrospray source. The samples were introduced by direct infusion in a solution of $\mathrm{MeOH}$ at a rate

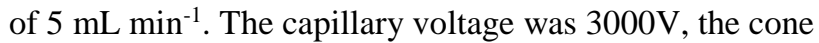
voltage was $35 \mathrm{~V}$, and the temperature was $80 \circ \mathrm{C}$. Optical rotations were determined in $\mathrm{MeOH}$ with a Perkin-Elmer 341 polarimeter. TLC was performed on pre-coated silicagel $60 \mathrm{~F}_{254}$ Merck. CC was carried out on Kieselgel 60 (63200 mesh) or LiChroprep RP-18 (40-63 $\mu \mathrm{m})$ Merck. HPLC was performed on a Dionex apparatus equipped with an ASI-100 autosampler, an Ultimate 3000 pump, a diode array detector UVD 340S and Chromeleon software. C18 reversed

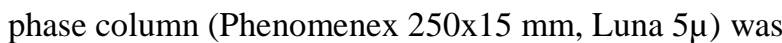
used for semi-preparative HPLC with binary gradient eluent $\left(\mathrm{H}_{2} \mathrm{O}\right.$ ( $\mathrm{pH} 2.4$ with TFA); $\mathrm{MeOH}$ ), a flow rate of $4 \mathrm{~mL} / \mathrm{min}$ and the chromatogram was monitored at 205, 225, 250 and $350 \mathrm{~nm}$

\subsection{Plant material}

The aerial parts of Gouania longipetala Hemsl. (Rhamnaceae) were collected at Bayota town, near Gagnoa city in the south-central Ivory Coast, in September 2009. The plant was identified by Pr. Laurent AKE-ASSI of FHB University and a voucher specimen (No Aké-Assi S.N-02) has been deposited in the herbarium of the National Center of Floristic of FHB University of Cocody (Ivory Coast).

\subsection{Extraction and isolation}

The dried powdered aerial parts of $G$. longipetala $(950 \mathrm{~g})$ were successively extracted with petroleum ether (PE), EtOAc and $\mathrm{MeOH}$ after maceration at room temperature for $24 \mathrm{~h}$ (19 $\mathrm{L}$ of each solvent). After evaporation of the solvents, $7.9 \mathrm{~g}$ of PE extract, $4.7 \mathrm{~g}$ of EtOAc extract and $26.5 \mathrm{~g}$ of $\mathrm{MeOH}$ extract were obtained.
The MeOH extract was subjected to VLC over RP-18 ( 9 x 5 $\mathrm{cm})$ eluted successively with 20, 40, 60, 80 and $100 \%$ $\mathrm{MeOH}$ in $\mathrm{H}_{2} \mathrm{O}$, to give five fractions $\left(\mathrm{A}_{1}-\mathrm{A}_{5}\right.$, respectively). Fraction $\mathrm{A}_{2}(2.3 \mathrm{~g})$ was applied to a RP-18 CC (2 x $\left.16 \mathrm{~cm}\right)$ eluted with a gradient of $\mathrm{MeOH}: \mathrm{H}_{2} \mathrm{O}(2: 8 \rightarrow 5: 5)$ to afford 130 fractions, each $30 \mathrm{~mL}$. Frs [55-80] (367 mg), eluted with $\mathrm{MeOH}: \mathrm{H}_{2} \mathrm{O}(35: 65)$, were purified by silica gel $\mathrm{CC}$ eluted with a gradient of $\mathrm{CHCl}_{3}: \mathrm{MeOH}(9: 1 \rightarrow 6: 4)$ to yield compound 2 (14 mg). Fraction $\mathrm{A}_{3}(5.5 \mathrm{~g})$ was applied to a silica gel VLC $\left(9\right.$ x $5 \mathrm{~cm}$ ) eluted with $\mathrm{CHCl}_{3}: \mathrm{MeOH}: \mathrm{H}_{2} \mathrm{O}$ $(9: 1: 0 \rightarrow 60: 40: 7)$ to give six fractions ( $\mathrm{B}_{1}-\mathrm{B}_{6}$, respectively), each $280 \mathrm{~mL}$. Fraction $\mathrm{B}_{5}(1.8 \mathrm{~g})$, eluted with $\mathrm{CHCl}_{3}: \mathrm{MeOH}$ ( $9: 1 \rightarrow 7: 3)$ was further purified over silica gel CC $(2.8 \times 24$ $\mathrm{cm}, 40$ fractions, each $100 \mathrm{~mL}$ ) to afford $64 \mathrm{mg}$ of compound 6 (eluted with 85:15 of $\mathrm{CHCl}_{3}: \mathrm{MeOH}$ ). Frs [5-9] (83 mg), eluted with $\mathrm{CHCl}_{3}: \mathrm{MeOH}(9: 1)$ were purified by semi-prep HPLC using $50 \%$ of $\mathrm{MeOH}$ for 30 min yielding compound 4 (rt $17.5 \mathrm{~min}, 16 \mathrm{mg}$ ). Frs [13-17] (331 mg), eluted with $\mathrm{CHCl}_{3}: \mathrm{MeOH}(85: 15)$ were applied to a silica gel $\mathrm{CC}$ eluted with a gradient of $\mathrm{CHCl}_{3}: \mathrm{MeOH}(9: 1 \rightarrow 7: 3)$ and further purified by semi-prep HPLC using $50 \%$ of $\mathrm{MeOH}$ for $45 \mathrm{~min}$ yielding compounds 5 ( $r t 12.5 \mathrm{~min}, 9$ $\mathrm{mg}$ ), 3 ( $r t 13.5 \mathrm{~min}, 8 \mathrm{mg}$ ), 1 (rt $21.1 \mathrm{~min}, 10 \mathrm{mg}$ ), and 7 ( $r t$ $32.5 \mathrm{~min}, 24 \mathrm{mg})$.

The EtOAc extract was subjected to VLC over silica gel $(9 \times 5 \mathrm{~cm})$ eluted successively with $1,2,3,5$, and $10 \% \mathrm{MeOH}$ in $\mathrm{CHCl}_{3}$. Fraction eluted with $5 \% \mathrm{MeOH}$ in $\mathrm{CHCl}_{3}(520 \mathrm{mg})$ was applied to a RP-18 CC $(1.8 \times 12.8 \mathrm{~cm})$ eluted with a gradient of $\mathrm{MeOH}: \mathrm{H}_{2} \mathrm{O}(6: 4 \rightarrow 9: 1)$. Fractions eluted with $\mathrm{MeOH}: \mathrm{H}_{2} \mathrm{O}$ (7:3) were further purified by semiprep HPLC using a gradient from 70 to $75 \%$ of $\mathrm{MeOH}$ in 20 min yielding compound $\mathbf{1 0}$ ( $r t 14.0 \mathrm{~min}, 6 \mathrm{mg}$ ). Fraction eluted with $10 \% \mathrm{MeOH}$ in $\mathrm{CHCl}_{3}(275 \mathrm{mg}$ ) was applied to a silica gel $\mathrm{CC}(1.8 \times 12.8 \mathrm{~cm})$ eluted with a gradient of $\mathrm{CHCl}_{3}: \mathrm{MeOH}(10: 0 \rightarrow 9: 1)$ yielding compounds $8(14 \mathrm{mg})$ and 9 ( $8 \mathrm{mg})$.

\subsection{Acid hydrolysis}


An aliquot of the crude saponin mixture $\left(\mathrm{A}_{2}\right.$ and $\mathrm{A}_{3}$ $500 \mathrm{mg}$ each) was refluxed $\left(90^{\circ} \mathrm{C}\right)$ with $50 \mathrm{~mL}$ of $2 \mathrm{M}$ TFA for $4 \mathrm{~h}$. After extraction with ethyl acetate $(3 \times 30 \mathrm{~mL})$, the aqueous layer was evaporated to furnish the monosaccharides residue $(300 \mathrm{mg})$. Four sugars were identified as arabinose, glucose, galactose and rhamnose by comparison with authentic samples on TLC in MeCOEt:isoPrOH:acetone: $\mathrm{H}_{2} \mathrm{O} \quad(20: 10: 7: 6)$. A part of the monosaccharides residue $(50 \mathrm{mg})$ was subjected to a preparative TLC using the same solvent. The optical rotation of each purified sugar was measured to reveal rhamnose $\left([\alpha]^{20}{ }_{\mathrm{D}}+2.4\left(c 1, \mathrm{H}_{2} \mathrm{O}\right)\right)$, glucose $\left([\alpha]^{20}{ }_{\mathrm{D}}+27.6(c\right.$ 0.75,

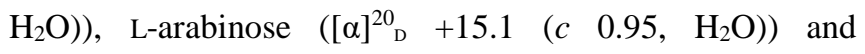
galactose $\left([\alpha]^{20}{ }_{\mathrm{D}}+41.2\left(c 1, \mathrm{H}_{2} \mathrm{O}\right)\right)$.

\subsection{Broth diffusion antibacterial assays.}

A serial dilution technique using 96-well microtiter plates was used to check the MIC of the pure compounds (110) against Staphylococcus aureus (CIP 53154), S. aureus (8325-4) and Enterococcus faecalis (ATCC 1054), for Gram positive and Escherichia coli (DH5- $\alpha$ ) for Gram negative, as previously described (Yao-Kouassi et al., 2008). Briefly, the mother compound solutions $(10 \mathrm{mg} / \mathrm{mL})$ were prepared by dissolving the compound in DMSO. Fifty microliters of each solution was added to $950 \mu \mathrm{L}$ of Muller-Hinton medium. This was serially diluted 2-fold with Muller-Hinton medium to obtain concentration ranges of 4 to $256 \mu \mathrm{g} / \mathrm{mL}$. Fifty microliters of each concentration was added in a well (96-well microplate) containing $150 \mu \mathrm{L}$ of Mueller-Hinton medium and $5 \mu \mathrm{L}$ of the standard bacterial inoculum. The negative control well consisted of $12.5 \mu \mathrm{L}$ of DMSO, 187.5 $\mu \mathrm{L}$ of Mueller-Hinton medium and $5 \mu \mathrm{L}$ of the standard bacterial inoculum. The plates were covered with a sterile plate sealer, then agitated and incubated at $37{ }^{\circ} \mathrm{C}$ for $18 \mathrm{~h}$. Microbial growth was determined by observing the deposit of the bacteria at the bottom of the wells. The lowest concentration inhibiting bacterial deposit was considered as the MIC. The experiments were run in triplicate for each compound on each strain, and each time the MIC values were identical. Gentamicin was used as positive control of bacterial growth inhibition in the same conditions.

\subsection{Cell proliferation assay.}

Promyelocytic leukemia HL60 and human erythromyeloblastoid leukemia K562 cells were spread onto 96-well flat-bottom plates at a density of 2500 cells per well, and then incubated for $24 \mathrm{~h}$ in RPMI 1640 Medium supplemented with $10 \%$ fetal bovine serum and antibiotics. After culture, the cells were treated with saponins for $72 \mathrm{~h}$. The cell cultures were then analyzed using 3-(4,5dimethylthiazol-2-yl)-5-(3-carboxymethoxyphenyl)-2-(4sulfophenyl)-2H-tetrazolium inner salt (MTS) according to the manufacturer's instructions (Promega Corporation, Charbonnières, France). Camptothecin was used as positive control with the same conduction. MTS is reduced by cells into a colored formazan product. Absorbance was analyzed at a wavelength of $540 \mathrm{~nm}$ with a Multiskan Ex microplate absorbance reader (Thermo Scientific, Paris, France). The results of these assays were used to obtain the dose-response curves from which $\mathrm{IC}_{50}$ values were determined. The values represent averages of three independent experiments.

3.7. Gouaniaside I (1): $[\alpha]^{20}-49.5$ (c $\left.0.69, \mathrm{MeOH}\right) ;{ }^{1} \mathrm{H}$ and ${ }^{13} \mathrm{C}$ NMR of the aglycone part $\left(\mathrm{CD}_{3} \mathrm{OD}, 500 \mathrm{MHz}\right)$, see Table $1 ;{ }^{1} \mathrm{H}$ and ${ }^{13} \mathrm{C}$ NMR of the glycosidic part, see Table 2; HR-ESI-MS $m / z: 789.4409\left[\mathrm{M}+\mathrm{Na}^{+}\right.$(calcd for $\left.\mathrm{C}_{41} \mathrm{H}_{66} \mathrm{O}_{13} \mathrm{Na}, 789.4401\right)$.

3.8. Gouaniaside II (2): $[\alpha]^{20}{ }_{\mathrm{D}}-55.8(c 0.17, \mathrm{MeOH}) ;{ }^{1} \mathrm{H}$ and ${ }^{13} \mathrm{C}$ NMR of the aglycone part $\left(\mathrm{CD}_{3} \mathrm{OD}, 500 \mathrm{MHz}\right)$, see Table $1 ;{ }^{1} \mathrm{H}$ and ${ }^{13} \mathrm{C}$ NMR of the glycosidic part, see Table 2; HR-ESI-MS $m / z: 771.4288\left[\mathrm{M}+\mathrm{Na}^{+}\right.$(calcd for $\left.\mathrm{C}_{41} \mathrm{H}_{64} \mathrm{O}_{12} \mathrm{Na}, 771.4295\right)$.

3.9. Gouaniaside III (3): $[\alpha]^{20}-62.3(c 0.55, \mathrm{MeOH}) ;{ }^{1} \mathrm{H}$ and ${ }^{13} \mathrm{C}$ NMR of the aglycone part $\left(\mathrm{CD}_{3} \mathrm{OD}, 500 \mathrm{MHz}\right)$, see Table $1 ;{ }^{1} \mathrm{H}$ and ${ }^{13} \mathrm{C}$ NMR of the glycosidic part, see Table 2; HR-ESI-MS $m / z: 933.4836\left[\mathrm{M}+\mathrm{Na}^{+}\right.$(calcd for : $\mathrm{C}_{47} \mathrm{H}_{74} \mathrm{O}_{17} \mathrm{Na}$, 933.4824).

3.10. Gouaniaside IV (4): $[\alpha]^{20}{ }_{\mathrm{D}}-45.2(c 0.27, \mathrm{MeOH}) ;{ }^{1} \mathrm{H}$ and ${ }^{13} \mathrm{C}$ NMR of the aglycone part $\left(\mathrm{CD}_{3} \mathrm{OD}, 500 \mathrm{MHz}\right)$, see Table $1 ;{ }^{1} \mathrm{H}$ and ${ }^{13} \mathrm{C}$ NMR of the glycosidic part, see Table 2; HR-ESI-MS $m / z$ : $975.4918\left[\mathrm{M}+\mathrm{Na}^{+}\right.$(calcd for : $\left.\mathrm{C}_{49} \mathrm{H}_{76} \mathrm{O}_{18} \mathrm{Na}, 975.4929\right)$.

3.11. Gouaniaside $\boldsymbol{V}(5)$ : $[\alpha]^{20}-20.5(c 0.34, \mathrm{MeOH}) ;{ }^{1} \mathrm{H}$ and ${ }^{13} \mathrm{C}$ NMR of the aglycone part $\left(\mathrm{CD}_{3} \mathrm{OD}, 500 \mathrm{MHz}\right)$, see Table $1 ;{ }^{1} \mathrm{H}$ and ${ }^{13} \mathrm{C}$ NMR of the glycosidic part, see Table 2; HR-ESIMS $m / z$ : $1097.5519[\mathrm{M}+\mathrm{Na}]^{+}$(calcd for : $\left.\mathrm{C}_{53} \mathrm{H}_{86} \mathrm{O}_{22} \mathrm{Na}, 1097.5508\right)$.

3.12. Gouaniaside VI (6): $[\alpha]^{20}{ }_{\mathrm{D}}-30.5(c 0.31, \mathrm{MeOH}) ;{ }^{1} \mathrm{H}$ and ${ }^{13} \mathrm{C}$ NMR of the aglycone part $\left(\mathrm{CD}_{3} \mathrm{OD}, 500 \mathrm{MHz}\right)$, see Table $1 ;{ }^{1} \mathrm{H}$ and ${ }^{13} \mathrm{C}$ NMR of the glycosidic part, see Table 2; HR-ESI-MS $m / z: 1111.5669[\mathrm{M}+\mathrm{Na}]^{+}$(calcd for : $\left.\mathrm{C}_{54} \mathrm{H}_{88} \mathrm{O}_{22} \mathrm{Na}, 1111.5665\right)$.

\section{Supporting Information}

HR-ESI-MS spectra and 1D and 2D NMR of 1-6.

\section{Acknowledgements.}

The authors are grateful to CNRS, Conseil Régional Champagne Ardenne, Conseil Général de la Marne, Ministry of Higher Education and Research (MESR), and to the PIANET CPER project for financial support. The authors warmly thank Chantal Grimplet for her technical assistance. 
Alabdul Magid, A., Morjani, H., Harakat, D., Madoulet, C., Dumontet, V., Lavaud, C., 2015. Triterpenoid glycosides from the leaves of Meliosma henryi. Phytochemistry 109, 49-56.

Backinowsky, L., Balan, N.F., Shashkov, A.S., Kochetkov, N.K., 1980. Synthesis and ${ }^{13} \mathrm{C}$ NMR spectra of $\beta$-Lrhamnopyranosides. Carbohydr. Res. 84, 225-235.

Brandao, M.G., Lacaille-Dubois, M.A., Teixeira, M.A., Wagner, H., 1993. A dammarane-type saponin from the roots of Ampelozizyphus amazonicus. Phytochemistry 34, 1123-1127.

Buerki, S., Philipson, P.B., Callmander, M.W., 2011. A taxonomic revision of Gouania (Rhamnaceae) in Madagascar and the other Islands of Western Indian ocean. Ann. Mo.Bot.Gard.98, 157-195.

Burkill, H.M., 1985. The Useful Plants of West Tropical Africa. The trustees of the Royal Botanical Garden, Kew, UK.

Ekuadzi, E., Dickson, R.A., Fleischer, T.C., 2012. Antibacterial, anti-inflammatory and antioxidant properties of Gouania longipetala Hemsl. IJPSR. 3, 1300-1305.

Ekuadzi, E., Dickson, R.A., Fleischer, T.C., Amponsah, I.K., Pistorius D. and Oberer L., 2014. Chemical constituents from Gouania longipetala and Glyphaea brevis. Nat. Prod. Res. 28, 1210-1213.

Ezeja, M.I., Anaga, A.O., Asuzu, I.O., 2014. Effect of Gouania longipetala (Hemsl.) methanolic leaf extract on the kidney and hematology of alloxan-induced hyperglycemic Wistar rats. Comp Clin Pathol, 23, 1697-1702.

Gossan, D.P.A., Alabdul Magid, A., Yao-Kouassi, P.K., Coffy, A.A., Harakat, D., Voutquenne-Nazabadioko, L. 2015. New acylated flavonol glycosides from the aerial parts of Gouania longipetala. Phytochemistry 11, 306-310.

Giacomelli, S.R., Maldaner, G., Stücker, C., Marasciulo, C., Schmidt, J., Wessjohann, L., Dalcol, I.I., Morel, A.F. 2007. Triterpenoids from Gouania ulmifolia. Planta Med. 73, 499-501.

Jossang, A., Seuleimann, M., Maidou, E., Bodo, B. 1996. Pentacyclic triterpenes from Combretum nigricans. Phytochemistry, 41: 591-594.

Kuang, H.X., Kasai, R., Ohtani, K., Liu, Z.S., Yuan, C.S., Tanaka, O.1989. Chemical constituents of pericarps of Rosa davurica Pall., a traditional Chinese medicine. Chem. Pharm. Bull. 37, 2232-2233.

Maciuk, A., Lavaud, C., Thepenier, P., Jacquier M.-J., Ghedira, K., Zeches-Hanrot, M. 2004. Four new dammarane saponins from Zizyphus lotus J. Nat. Prod. 67, 1639-1643.

Perera, P., Andersson, R., Bohlin, L., Andersson, C., Li, D., Owen, N.L., Dunkel, R., Mayne, C.L., Pugmire, R.J., Grant, D.M., Cox, P.A., 1993. Structure determination of a new saponin from the plant Alphitonia zizyphoides by NMR spectroscopy. Magn. Reson. Chem. 31, 472-
480. Renault, J.-H., Ghedira, K., Thepenier, P., Lavaud, C., Zeches-Hanrot, M., Le Men-Olivier, L. 1997. Dammarane saponins from Zizyphus lotus. Phytochemistry 44, 1321-1327.

Suksamrarn, S.,Panseeta, P., Kunchanawatta, S., Distaporn, T.,Ruktasing, S., Suksamrarn, A., 2006.Ceanothaneand lupane-type triterpenes with antiplasmodial and antimycobacterial activities from Ziziphus cambodiana. Chem Pharm Bull 54, 535-537.

Wang, Y., Ding, B., Luo, D., Chen, L.Y., Hou, Y.L., Dai, Y.,Yao, X.S., 2013. New triterpene glycosides from Ziziphi Spinosae Semen. Fitoterapia 90, 185-91.

Wu, Y., Zhang, J., Wang, D., Liu, L.J., Hu, Y., 2013. Triterpenoid saponins from Ziziphus jujuba var. spinose. Chem. Nat. Comp.49, 677-681.

Yao-Kouassi, P.A., Alabdul Magid, A., Richard, B., Martinez, A., Jacquier, M.J., Caron, C., Le Magrex Debar, E., Gangloff, S.C., Coffy, A.A., ZèchesHanrot, M., 2008. Isoflavonoid glycosides from the roots of Baphia bancoensis. J. Nat. Prod. 71, 20732076.

Yoshikawa, K., Shimono, N., Arihara, S., 1992. Antisweet natural products. VI: Jujubasaponins IV, V and VI from Zizyphus jujuba MILL. Chem. Pharm. Bull. 40, 2275-2278. 